\title{
O PERFIL DOS HOMICÍDIOS FEMININOS NO RECIFE E REGIÃO METROPOLITANA
}

\author{
Gisele Calado da Silva Barros ${ }^{1}$ \\ Wagner Pereira da Silva²
}

\section{RESUMO}

Este estudo traçou o perfil das mulheres vítimas de homicídios em Recife e Região Metropolitana do Recife (RMR), Pernambuco. Realizou-se um estudo descritivo, retrospectivo, incluindo todas as mulheres residentes em Recife e RMR, com idade a partir de 13 anos, vítimas de homicídios, no período de 01 de janeiro de 2014 a 31 de janeiro de 2015. O meio utilizado para coleta de informações foi a consulta à Gerência de Análise Criminal e Estatística, através da base de dados criminais do estado, pelo Sistema INFOPOL que relata os números referentes as mulheres vítimas de Crimes Violentos Letais Intencionais e suas variáveis, tais como: número de homicídios por idade, localidade e horários de ocorrência, cor da pele e objeto utilizado no crime. Identificaram-se 123 óbitos por homicídios no período do estudo. A maioria das vítimas era adulta jovem, parda, locada no Recife, assassinadas em sua grande maioria por arma de fogo, no final de semana durante a madrugada. A predominância dos homicídios na faixa etária de mulheres jovens adultas na cor parda confirma a existência da desigualdade racial. O grande número de homicídios causados por arma de fogo revela a facilidade de acesso e a disponibilidade de armas no País.

Palavras-chave: Feminicidio, Violência de gênero, Saúde pública, Segurança pública, Homicídio feminino.

\footnotetext{
${ }^{1}$ Residente em Nefrologia no Instituto Materno Infantil de Pernambuco. Bacharela em Enfermagem UNINASSAU. Email: caladogisele@gmail.com

${ }^{2}$ Major do Corpo de Bombeiros Militar de Pernambuco. Mestre em Ciência da Saúde - UPE, Professor de Urgência e Emergência - UNINASSAU. Email: wag_per@yahoo.com.br
} 


\title{
THE PROFILE OF FEMALE HOMICIDES IN RECIFE AND METROPOLITAN REGION
}

\begin{abstract}
This study traced the women victims' profile of homicide in Recife and the metropolitan area (RMR) in Pernambuco. Conducted a descriptive, retrospective study, including all women living in Recife and RMR (Metropolitan Area), aged from 13 years old, all then homicides victims in the period from January $1^{\text {st }}, 2014$ until January $31^{\text {st }}, 2015$. The way used for gathering information was a Criminal Analysis Management and Statistics consult, through the State's criminal database, according to INFOPOL system that reports the figures for women victims of Violent Crimes Lethal Intentional and its variables, such as Homicides numbers according to the age, location and event schedules, skin color and object used in the crime. Identified 123 homicides' deaths in the period of this study. Most of the victims were young adult, brown skin, leased in the city (Recife), and killed mostly by firearms (guns) and on the weekend overnight. The predominance of homicides in the young adult age and brown skin color just confirms the racial inequality existence. These homicides caused numbers by firearms reveals the ease access and availability of weapons in the country.
\end{abstract}

Keywords: Femicide. Gender Violence. Public Health. Public Security, Female Homicide.

Artigo recebido em 29/03/16 e Aceito em 22/10/16. 


\section{INTRODUÇÃO}

O homicídio feminino é uma causa de morte crescente em nossa população. Considerado como um problema de saúde pública, o conceito de violência homicida contra as mulheres nomeada violência de gênero, se faz presente desde 1990. Femicídio e feminicídio são sinônimos utilizados para caracterizar crimes derivados de hostilidade de gênero, termo de cunho político e legal (KRUG, 2003; SAGOTM, 2000).

O termo foi citado pela primeira vez por Diana Russel ${ }^{2,}$ em 1976 em um fórum de feministas no qual se reuniam representantes de 40 países, sob o nome de Tribunal Internacional de Crimes Contra as Mulheres, em Bruxelas. $\mathrm{Na}$ oportunidade, a condição do gênero se reportava como determinante em relação aos crimes contra as mulheres (CARCEDO, 2000).

Esses crimes passaram a ser punidos com mais rigor a partir da lei 11.340/2006, conhecida como lei Maria da Penha (BRASIL, 2006), que tem como objetivo coibir e prevenir a violência doméstica e familiar contra as mulheres. Por ocasião da existência de tal dispositivo legal, várias controvérsias foram geradas no tocante a sua aplicabilidade e conflitos em sua interpretação, entretanto sua importância é indiscutível, tendo em vista o nítido avanço na análise e discussão dos crimes próprio de violência doméstica. Com a sanção presidencial, o feminicídio é tipificado no Código Penal brasileiro como crime hediondo. A lei 13.104/15 expõe e qualifica o homicídio de mulheres em decorrência de violência doméstica ou em contexto de discriminação (BRASIL, 2015).

Estudos internacionais mostraram que a violência contra as mulheres é muito mais grave e generalizada do que se suspeitava anteriormente. ${ }^{6}$ De acordo com o Prehospital Trauma Life Suport - PHTLS (Atendimento Préhospitalar ao Traumatizado) na maioria dos países, independentemente de seu 
nível de desenvolvimento, traumas aparecem entre as cinco principais causas de mortes (PHTLS, 2007).

O Brasil está entre os países de maior índice de homicídios femininos, ocupando o sétimo lugar no ranking de 84 nações, dados disponibilizados no mapa de violência mostraram um aumento de 2,3 para 4,8 assassinatos por 100 mil habitantes entre 1980 e 2012, tornando-se ainda mais alarmante na população jovem feminina, em que só no ano de 2012 existiram 7,7 execuções a cada 100 mil habitantes. A cada quatro horas uma mulher com idade abaixo de 30 anos é assassinada, sendo tais ilícitos $60 \%$ maiores nessa faixa etária. De 1996 a 2010 as taxas permaneceram estabilizadas em torno de 4,5 homicídios para cada 100 mil mulheres (BRASIL, 2012).

O estado de Pernambuco ocupou o segundo lugar entre os estados brasileiros com coeficiente de execuções femininas de 6,63 por $100 \mathrm{mil}$ habitantes nos anos de 2003/2007. Recife ocupa o segundo posto entre as capitais brasileiras de maior risco para esse tipo de violência letal. Os homicídios consumados por desconhecidos em espaços públicos vêm sendo observados no estado, seja por sua relação afetiva ou familiar, pelo envolvimento com o crime organizado ou resultante da elevada violência urbana (MENEGUEL, 2011; BRASIL, 2010). Em 2010 na análise dos assassinatos femininos, Pernambuco ocupou o décimo lugar com taxas de 5,4 por 100 mil mulheres e Recife o décimo terceiro lugar, com taxas de 6,1 por 100 mil mulheres (SOARES, et. al., 2007).

No momento em que a enfermagem revela seu potencial de cuidado com o próximo, o detalhamento dessa temática trazido com o presente estudo estabelece um meio fundamental para melhoria nas intervenções à serem feitas pelo enfermeiro, no atendimento à população feminina vítima de violência, com a finalidade de reduzir este agravo em todo território nacional. A condição plural da violência requer o conhecimento da população vitimada, do agressor e das circunstâncias pela qual ocorre. A relevância da violência social 
na cidade do Recife e Região Metropolitana, em que se destaca a magnitude crescente de ilícitos contra as mulheres, uma vez que este grupo apresenta uma aparente vulnerabilidade nesse quesito. Diante de tais aspectos, 0 presente estudo objetivou traçar o perfil dos homicídios femininos na cidade do Recife e Região Metropolitana.

\section{MATERIAIS E MÉTODOS}

Foi realizado um estudo do tipo descritivo e retrospectivo que relaciona a mortalidade feminina por agressão no período de 01 janeiro de 2014 a 31 janeiro de 2015, correspondente ao lapso temporal mais próximo registrado na base de dados consultada do início das pesquisas referentes a este trabalho além da nítida necessidade de serem analisadas informações recentes dessa problemática de saúde pública, devido à escassez de estudos atualizados no Recife e RMR, descrevendo o perfil e características das vítimas de homicídios. O sitio da pesquisa foi a cidade do Recife, capital do estado de Pernambuco, metrópole com destacada posição na região nordeste do Brasil. Foram incluídas todas as mulheres com idade a partir de 13 anos, residentes na cidade do Recife e Região Metropolitana do Recife (RMR), submetidas à necropsia na unidade do Instituto Médico de Medicina Legal (IML), único serviço desta natureza na cidade. O estudo foi aprovado pelo Comitê de Ética em pesquisa do Centro Universitário Mauricio de Nassau (UNINASSAU), sob protocolo 50892815.9.0000.5193. Ressalta-se que na operacionalização do estudo desta pesquisa não houve abordagem de seres humanos por serem utilizados apenas dados secundários do Sistema INFOPOL.

O meio utilizado para coleta de informações foi a consulta à Gerência de Análise Criminal e Estatística (GACE), através da base de dados criminais do estado de Pernambuco fornecida no relatório no 398/2015/GACE/SDS-PE, de 22 de junho de 2015, onde constava os dados referentes ao período de 01 
janeiro de 2014 a 31 janeiro de 2015, pelo Sistema INFOPOL, um portal da Secretaria de Defesa Social para acesso a análises criminais e boletins de ocorrências registradas e acontecidas em Pernambuco, onde se utilizou dos números referentes as mulheres vítimas de Crimes Violentos Letais Intencionais (CVLI). Os homicídios foram analisados segundo a cor da pele, idade, localidades (municípios), período do dia e objeto utilizado nos crimes. A variável "período do dia" foi dividida em duas categorias: dia da semana e turno. Com a finalidade de facilitar a compreensão das informações levantadas foram utilizados três gráficos e uma tabela nos quais foram expostos os dados calculados por proporção buscando relacionar a quantidade total de homicídios femininos e o índice apresentado por cada elemento variante.

Estudos científicos similares a este foram encontrados e usados para comparar o perfil das vítimas em anos anteriores a esta pesquisa, destacandose o estudo realizado por Silva et al no Instituto de Medicina Integral Professor Fernando Figueira que buscou referenciar as peculiaridades envolvendo as mulheres vítimas de assassinatos em Recife entre os anos de 2010/2011 e da Universidade Federal de Pernambuco, realizado por Silva et al que descreveu e analisou as Declarações de Óbitos (DO) de mulheres em idade fértil. Outras fontes baseadas na temática "homicídios femininos" na região estudada foram fundamentais na discussão desta pesquisa pois se acredita que quanto mais análises sobre $o$ assunto forem realizadas mais visibilidade será concedida a tais crimes, perpetuados de forma cruel.

\section{RESULTADOS E DISCUSSÃO}

Recife é uma capital sabidamente violenta, onde o seguimento feminino aparece como um dos grupos mais expostos, figurando no topo do cenário das elevadas taxas de homicídios. Os resultados apresentados a seguir referem-se 
aos homicídios de 01 de janeiro de 2014 a 31 de janeiro de 2015 nos quais foram evidenciadas 123 vítimas de Crimes Violentos Letais Intencionais.

Em relação a faixa etária (Tabela 1), a proporção maior observada foi entre 18 e 30 anos com $47,2 \%$ o que confirma que este grupo vem sendo o mais vulnerável dos últimos estudos, sendo a cor parda a de maior prevalência com $93,7 \%$.

\section{Tabela 1 - Incidência de homicídios femininos relacionada a fatores sócio demográficos}

\begin{tabular}{lcc}
\hline \multicolumn{1}{c}{ Variável } & Quantidade & Porcentagem \\
\hline Cor da pele & & $1,5 \%$ \\
\hline Branca & 2 & $93,7 \%$ \\
\hline Parda & 119 & $4,7 \%$ \\
\hline Não informado & 6 & $11,8 \%$ \\
\hline ldade & 15 & $47,2 \%$ \\
\hline $\begin{array}{l}\text { Adolescente } \\
\text { (13-17 anos) }\end{array}$ & 60 & $29,9 \%$ \\
\hline $\begin{array}{l}\text { Adulto-jovem } \\
\text { (18-30 anos) }\end{array}$ & 38 & $3,1 \%$ \\
\hline $\begin{array}{l}\text { Adulto (31-65 } \\
\text { anos) }\end{array}$ & 4 & $4,7 \%$ \\
\hline $\begin{array}{l}\text { Idoso (acima de } \\
65 \text { anos) }\end{array}$ & 6 & \\
\hline Não informado & 6 & \\
\hline
\end{tabular}

Fonte: Gerência de Análise Criminal e Estatística (GACE). Relatório no 398/2015/GACE/SDSPE - Sistema Infopol/GACE/SDS. Dados extraídos em 22JUN15.

É fundamental observar com a mesma importância dos demais fatores contribuintes para prática dos assassinatos femininos, que existe uma enorme diferença socioeconômica e demográfica no Recife, local onde as pessoas são próximas territorialmente, mas separadas pelas desigualdades sociais. Estudo realizado por Holmes CEM, 2012 na capital pernambucana, mostrou que os homicídios se reportam aos grupos menos favorecidos. Dados transversais observados no triênio 2001-2003 expõem as causas externas de mortes 
Revista Científica do Corpo de Bombeiros Militar de Pernambuco

Seção 1 - Artigos Técnico Científicos

Artigo publicado no Vol.03 №06 - Edição de JAN a JUN 2017 - ISSN 2359-4829

Versão on-line disponível em: http://www.revistaflammae.com

(fatores cujo conceito se refere a mortalidade por assassinatos e suicídios, agressões físicas e psicológicas, acidente de transito, quedas, afogamentos entre outros) do seguimento feminino, sendo os homicídios o terceiro responsável pelas mortes de mulheres especificamente negras e o sétimo, de mulheres brancas, reiterando a presença da desigualdade racial (SANTOS, 2007).

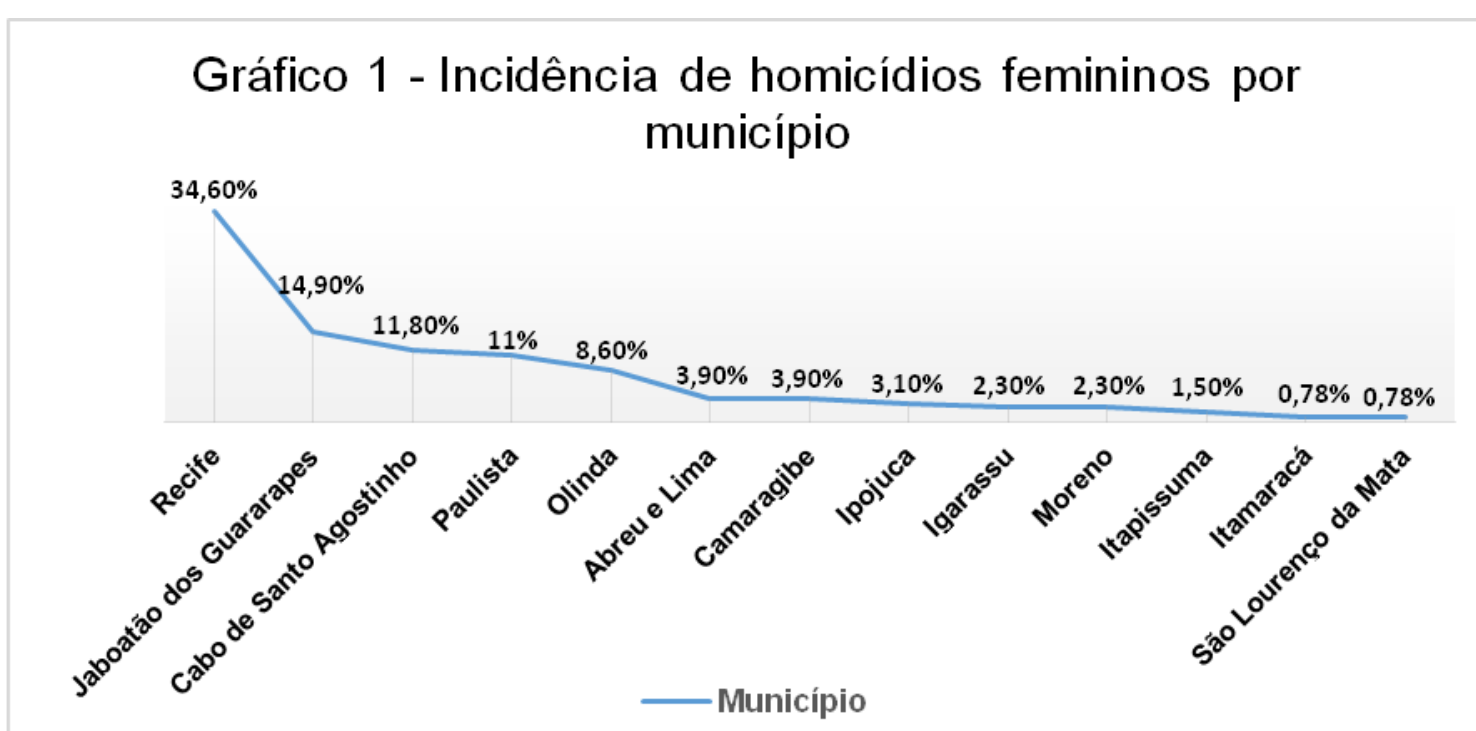

Fonte: Gerência de Análise Criminal e Estatística (GACE). Relatório no 398/2015/GACE/SDSPE - Sistema Infopol/GACE/SDS. Dados extraídos em 22JUN15.

Os números dos homicídios reproduzem taxas ascendentes tanto no Recife e Região Metropolitana quanto no Brasil, a estatística elevada de mortalidade na população feminina evidencia uma transformação nesse grupo apresentada como consequência da emancipação sexual feminina, da inserção desse seguimento no mercado de trabalho e do declínio na fecundidade, mudanças que justificam essas alterações no padrão do índice de mortes desse grupamento. Desde a década de 80 , entre as capitais, as mulheres 
Revista Científica do Corpo de Bombeiros Militar de Pernambuco

Seção 1 - Artigos Técnico Científicos

Artigo publicado no Vol.03 №06 - Edição de JAN a JUN 2017 - ISSN 2359-4829

Versão on-line disponível em: http://www.revistaflammae.com

pardas e negras de Recife são detentoras das maiores taxas de assassinatos (JACOBO, 2007).

Constatou-se em estudo feito no período de 2000-2001 na Zona da Mata de Pernambuco (ZMP) que a situação mais frequente de violência contra a mulher é a espécie conceituada como psicológica exclusiva, seguida pela física acompanhada da sexual e por fim pela violência que utiliza as três formas juntas, a amostra foi composta por mulheres em idade de 15 a 49 anos, excluindo a RMR (SCHRAIBER, et. al., 2007).

Quanto ao dia da semana, o final de semana seguido da segunda-feira, corresponde ao período que apresenta o maior número dos assassinatos de mulheres, concentrando $48,8 \%$ e $15,7 \%$ respectivamente. Na distribuição por turno, os atos criminosos aconteceram em sua maior parte na madrugada com $31.5 \%$ e à noite com $27,5 \%$ dos casos (Gráfico 2 ).

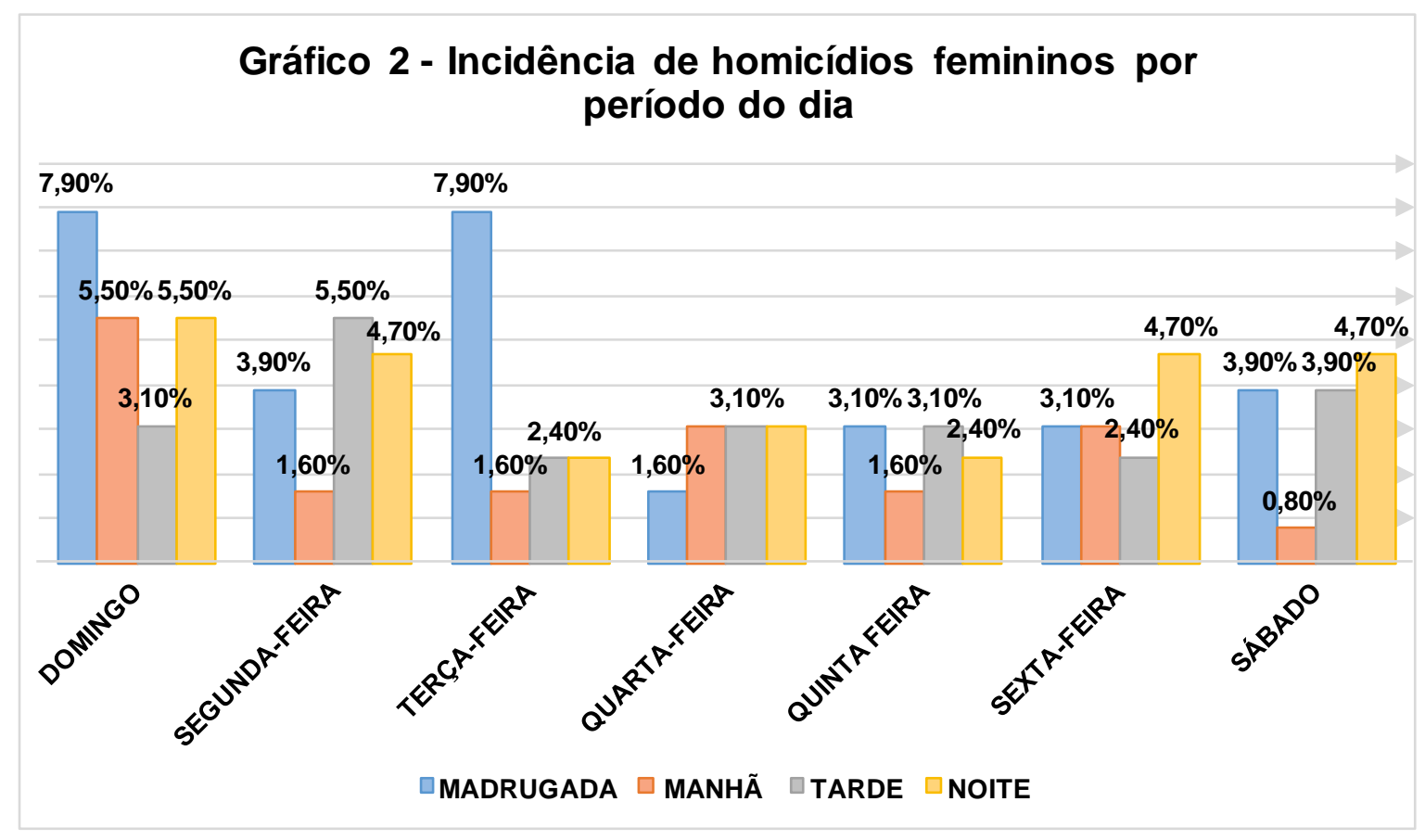

Fonte: Gerência de Análise Criminal e Estatística (GACE). Relatório no 398/2015/GACE/SDSPE - Sistema Infopol/GACE/SDS. Dados extraídos em 22JUN15. 
Revista Científica do Corpo de Bombeiros Militar de Pernambuco

Seção 1 - Artigos Técnico Científicos

Artigo publicado no Vol.03 №06 - Edição de JAN a JUN 2017 - ISSN 2359-4829

Versão on-line disponível em: http://www.revistaflammae.com

Os nossos achados assemelham-se com a pesquisa realizada através de publicações em jornais pernambucanos incluindo ainda os homicídios divulgados oficialmente pela Secretaria de Defesa Social (SDS) na qual verificou-se que em todo o período, Recife é o município que apresenta maior parte dos assassinatos (PORTELLA, 2002-2004). Aprofundando as avaliações desse contexto, concluiu-se que $59,8 \%$ das mortes ocorreram no final de semana, $41,5 \%$ no período da madrugada, sendo a arma de fogo responsável por $68 \%$ do total de casos e em relação ao dia da semana a concentração dos homicídios de mulheres centralizada nos fins de semana confirma a ideia da estreita relação do período de mais contato entre os casais com a maior probabilidade de ocorrência de conflitos.

Entre os instrumentos utilizados, as armas de fogo foram os principais meios aplicados nos homicídios femininos, responsáveis por $60,6 \%$, seguidas das armas brancas que responderam por $21,2 \%$ e outros tipos de objetos com 18,1\% (Gráfico 3).

\section{Gráfico 3 - Objetos utilizados nos homicídios femininos}

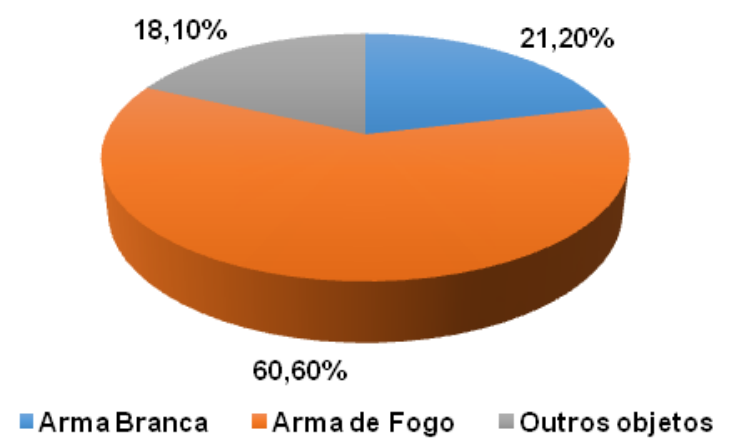

Fonte: Gerência de Análise Criminal e Estatística (GACE). Relatório no 398/2015/GACE/SDSPE - Sistema Infopol/GACE/SDS. Dados extraídos em 22JUN15.

Análise feita em Recife no quinquênio 2003-2007 mostrou uma maior incidência dos homicídios femininos em mulheres com menos de 30 anos 
Revista Científica do Corpo de Bombeiros Militar de Pernambuco

Seção 1 - Artigos Técnico Científicos

Artigo publicado no Vol.03 №06 - Edição de JAN a JUN 2017 - ISSN 2359-4829

Versão on-line disponível em: http://www.revistaflammae.com

contabilizando $64,2 \%$ dos casos, com $82,5 \%$ provocados por arma de fogo. Em observação ao local da ocorrência, a residência se destacou com $61,8 \%$ dos fatos (SILVA et al, 2011). De modo similar, estudo descritivo realizado em 2009-2010 revelou que a maioria das vítimas tinham entre 12 e 48 anos, com média de 27 anos, na cor parda e negra e os instrumentos utilizados nos crimes foram principalmente as armas de fogo seguida das armas brancas. Constatações que auxiliam no modo de situar os ilícitos na configuração espacial exploradas no presente estudo (SILVA, 2013).

Os efeitos deletérios causados pelas armas de fogo são evidenciados em 1960 e 2000, quando esse tipo de instrumento foi responsável por $28,4 \%$ e 90\% do total de mortes, respectivamente. Em 1997, no Recife, as armas de fogo foram responsáveis por $97 \%$ dos assassinatos em menores de 20 anos (Falbo GH, 2001). Gawryszewski et al, 2005 demonstrou com dados semelhantes a elevada frequência da utilização das armas de fogo nos casos de homicídios em nosso País, motivo pelo qual se torna essencial a frequente fiscalização das políticas de controle de aquisição e porte desse instrumento no Brasil.

A relação do assunto com a esfera socioeconômica do estado demonstra números alarmantes em que se prova o elevadíssimo custo social e econômico gerado a partir da violência contra as mulheres através dos gastos com assistência à morbidade, mortalidade e comorbidades, além da assistência social e judiciária aos agressores e vítimas, podendo remeter a incapacidade passageira ou permanente, no trabalho, no cuidado com os filhos ou até mesmo no próprio cuidado da vítima. Em 2011 a violência contra as mulheres causou um gasto de 5,3 milhões aos cofres públicos somente com internações, o dado foi calculado pelo Ministério Público a pedido da Agência Brasil (Brasil, 2012). Foram 5.496 mulheres internadas no Sistema Único de Saúde em decorrência de agressões (LINDA, 2007; KRUG, 2002). 
A variável que apresentou a associação mais importante e o maior nível de significância foi a mortalidade feminina analisada a partir da cor da pele. É possível observar dentro dos índices e definições citados no atual estudo, a relação da desigualdade racial com a criminalidade violenta no meio feminino. Considerando a hipótese dessa disparidade provocar bloqueio no desenvolvimento do avanço conjunto de uma população, se obtém como consequência a interferência negativa diante das oportunidades de melhoria da qualidade de vida. Essa correlação nos faz reconhecer que a distribuição do crime e da violência obedece a um certo padrão de incidência no meio detentor de menores condições socioeconômicas, resultado esse evidenciado nos demais estudos em consonância com a presente pesquisa.

A partir destas constatações é unanime o reconhecimento da associação direta entre a desigualdade social e a violência acometida contra as mulheres, porém não há bases suficientes para firmá-la como fonte geradora desse fenômeno criminoso. Embora os avanços para a redução das disparidades tenham sido mais visíveis nos últimos anos, o que se percebe diante dos dados levantados é uma recorrência de situações crônicas graves e bem estabelecidas.

Este estudo nos revela o perfil da maior parte das vítimas de homicídio no Recife e RMR, expondo como principais características a idade correspondente a classe "jovem-adulta", de cor parda, assassinadas em sua grande maioria por arma de fogo, no final de semana durante a madrugada. A predominância desses atos criminosos no referido grupo, nos implica reconhecer o crescimento da violência contra as mulheres. A incidência dos crimes na faixa etária jovem prejudica e ameaça os índices de produtividade, afeta a expectativa de vida, e altera os indicadores de produção e de qualidade de vida do País. O grande número de assassinatos causados por arma de fogo acentua a facilidade do acesso e a disponibilidade de porte desse instrumento no país. 


\section{CONSIDERAÇÕES FINAIS}

A violência é, antes de tudo, uma privação. No tocante aos homicídios femininos, a presença de uma legislação de direitos humanos das mulheres remete um grande avanço da sociedade na luta contra a discriminação e invisibilidade na punição da violência de gênero no âmbito do ordenamento jurídico. Desse modo, a reflexão agora normatizada demonstra a necessidade particular da execução de projetos e atividades em geral que possam garantir o direto e proteção à vida.

Diante dos dados e estudos avaliados é congruente o reconhecimento do altíssimo índice de violência contra as mulheres, embora os meios utilizados para averiguação sejam distintos, descrevem a recorrência de tais fenômenos criminosos nessa parcela da sociedade. Apesar dos avanços, lidar com os assassinatos femininos requer enfrentamento de diversas dificuldades, pela grande magnitude de sua reincidência. Por se tratar de um estudo descritivo, quantitativo, não foi possível construir um aprofundamento maior nas interpretações dos dados que envolvem a violência de gênero.

Portanto, após análise e avaliação das informações expostas nesse trabalho pode-se constatar a imprescindibilidade da instituição e fiscalização das políticas públicas de aquisição e porte de armas de fogo e de combate à desigualdade social econômica e racial no Recife e RMR, atitudes determinantes para modificação e melhoria desse cenário ainda sombrio observado nessa Região. Desta maneira, associações efetivas entre diversos setores governamentais ou não, devem ser construídas e firmadas atuando de maneira preventiva, construindo uma nova cidadania.

Nesse sentido, se demonstra a importância deste trabalho para o setor de saúde pública, incluindo-se a área de Enfermagem, podendo subsidiar a implementação de novas medidas de enfretamento dessa problemática nesse espaço geográfico. O enfermeiro como profissional da saúde que mantém 
contato diário no atendimento desta população específica, em qualquer que seja o nível de complexidade, deve estar inserido nesta discussão para aprofundamento na temática, permitindo reconstruir conceitos sobre a violência, com vistas a reduzir este agravo e mudar a realidade social. Para que os profissionais de saúde reconheçam a violência e cuidem das vítimas, é preciso adquirir conhecimento sobre os aspectos assistências e legais, bem como treinar a equipe de forma a capacitar seus membros para tal. No mais, sugere-se a realização de novos estudos instituidores de políticas de prevenção e controle da violência homicida contra as mulheres na região estudada.

\section{REFERÊNCIAS BIBLIOGRÁFICAS}

BRASIL. Lei o 11.340, de 7 de agosto de 2006. Dispõe sobre a criação dos juizados de Violência Doméstica e Familiar contra a Mulher; altera o código de processo penal e a Lei de Execução Penal e dá outras providências, 2006.

. Lei o 13.104, de 9 de março de 2015 altera o art. 121 do Decreto-Lei no 2.848, de 7 de dezembro de 1940 - Código Penal, para prever o feminicídio como circunstância qualificadora do crime de homicídio, e o art. 1 da Lei no 8.072, de 25 de julho de 1990, para incluir o feminicídio no rol dos crimes hediondos.

Mapa da Violência 2012: Os novos Padrões da Violência Homicida

no Brasil. Caderno complementar 1. Homicídio de mulheres no Brasil. 2012. Disponível em: http://www.mapadaviolencia.org.br. Acesso em: 02 set 15. 
Departamento de Análise e situação de Saúde, Secretaria de Vigilância em Saúde, Ministério da Saúde. Saúde Brasil 2008: uma análise da situação de saúde. Brasília: Ministério da Saúde; 2010.

CARCEDO, A.; SAGOT, M. Femicidio en Costa Rica 1990-1999. Washington, DC: Organización Panamericana de la Salud; (Colección Teórica,1), 2000.

FALBO G.H; BUZZETTI, R; CATTANEO A. Homicide in Children and adolescents: a case-control study in Recife, Brazil. Bull World Health Organ; 79:2-7, 2001.

GAWRYSZEWSKI V.P.; KAHN T.; MELLO, Jorge M.H.P. Informações sobre homicídios e sua integração com o setor saúde e segurança pública. Revista Saúde Pública; 39:627-33, 2005.

HOLMES, C.E.M. Anos potenciais de vida perdidos - APVP: análise das desigualdades segundo estrato da condição de vida na cidade do Recife. Dissertação de Mestrado - Recife: Programa Integrado de Pós-graduação em Saúde Coletiva, Centro de Ciências da Saúde, Universidade Federal de Pernambuco, 2002.

JACOBO, Julio W. Mapa da violência dos municípios brasileiros. Brasília, DF:OEI, 2007.

LINDA L.D.; ETIENNE, G.K. Violência: um problema global de saúde pública. Ciência \& Saúde coletiva; 11(sup): p. 1163, 2007

KRUG E.; DAHLBERG L.; MERCY J.; ZWI A.B.; LOZANO, J.A. Informe mundial sobre la violencia y la salud. Washington, DC: Organização Panamericana de la Salud, 2003.

KRUG, E.G.; DAHLBERG, L.L.; MERCY, JÁ, ZWI AB, Lozano R. Relatório Mundial sobre Violência e Saúde. Genebra: OMS; 2002

MENEGHEL, S.N; HIRAKATA, V.N. Femicídios: homicídios femininos no Brasil. Revista Saúde Pública; 45:564-74, 2011. 
PHTLS (Prehospital Trauma Life Support). Committee of the National Association of emergency Medical Technicians in Cooperation with the Committee on Trauma of the American College of Surgeons. 6. ed. Mosby: [s.n.], 2007.

PORTELLA A.P. Homicídios de mulheres em Pernambuco, 2002-2004: uma caracterização a partir de notícias de jornais. SOS Corpo; 2005. Disponível em: http://www.violenciamulher.org.br. Acesso em: 10 set 15.

SAGOT, M; CARCEDO, A. Ruta crítica de las mujeres afectadas por la violencia intrafamiliar en América Latina: estudios de caso de diez países. Washington: Organización Panamericana de la salud, 2000.

SANTOS S.M; GUIMARÃES, M.J.B.; ARAÚJO, T.V.B. Desigualdades raciais na mortalidade de mulheres adultas no Recife, 2001 a 2003. Saúde Sociedade; 16:87-102, 2007.

SCHRAIBER L.B; D'OLIVEIRA A.F.P.L; FRANÇA JUNIOR I.; DINIZ S; PORTELLA A.P.; LUDEMIR A.B.. Prevalência da violência contra a mulher por parceiro íntimo em regiões do Brasil. Revista Saude Pública,41(5):797-807, 2007.

SILVA L.S.; MENEZES M.L.N.; ALMEIDA LOPES C.L.; CORRÊA M.S.M. Anos potenciais de vida perdidos por mulheres vítimas de homicídios na cidade do Recife, Pernambuco, Brasil. Caderno de Saúde Pública, Rio de janeiro, setembro; 27(9), 2011.

SILVA M.A.; FILHO J.E.C.; AMORIM M.M.R.; NETO H.F. Mulherers vítimas de homicídio em Recife, Pernambuco, Brasil, 2009/2010: um estudo descritivo. Caderno de Saúde Pública, Rio de Janeiro, fevereiro; 29(2), 2013.

SOARES FILHO, A.M; SOUZA M.FM; CARVALHO C.G.; MALTA, D.C.; ALENCAR A.P.; SILVA, M.M.A. Análise da mortalidade por homicídios no Brasil. Epidemiologia e Serviços de Saúde. janeiro/março n.1, v.16, 2007.

WATTS, C.; ZIMMERMAN C. Violence against women: global scope and magnitude. Lancet., 359 (9313):1232-7, 2002 